\title{
Candidate gene/loci studies in cleft lip/palate and dental anomalies finds novel susceptibility genes for clefts
}

Alexandre R. Vieira, DDS, MS, PhD ${ }^{1,2,3,4}$, Toby G. McHenry, BS ${ }^{1,3}$, Sandra Daack-Hirsch, RN, PhD ${ }^{5}$, Jeffrey C. Murray, $M D^{5}$, and Mary L. Marazita, $P h D^{1,3,4,6}$

\begin{abstract}
Purpose: We revisited 42 families with two or more cleft-affected siblings who participated in previous studies. Complete dental information was collected to test the hypothesis that dental anomalies are part of the cleft phenotype spectrum, and can provide new opportunities for identification of cleft susceptibility genes. Methods: Genotypes from 1489 single nucleotide polymorphism markers located in 150 candidate genes/loci were reanalyzed. Two sets of association analyses were carried out. First, we ran the analysis solely on the cleft status. Second, we assigned affection to any cleft or dental anomaly (tooth agenesis, supernumerary teeth, and microdontia) and repeated the analysis. Results: Significant over-transmission was seen for a single nucleotide polymorphism in ankyrin repeat and sterile alpha motif domain containing 6 ( $r 44742741,9 q 22.33 ; P=0.0004$ ) when a dental anomaly phenotype was included in the analysis. Significant over-transmission was also seen for a single nucleotide polymorphism in ERBB2 ( $r$ 1810132, 17q21.1; $P=0.0006)$. In the clefts only data, the most significant result was also for ERBB2 $(P=0.0006)$. Other markers with suggestive $P$ values included interferon regulatory factor 6 and $6 q 21-q 23$ loci. In contrast to the above results, suggestive over-transmission of markers in GART, DPF3, and neurexin 3 were seen only when the dental anomaly phenotype was included in the analysis. Conclusions: These findings support the hypothesis that some loci may contribute to both clefts and congenital dental anomalies. Thus, including dental anomalies information in the genetics analysis of cleft lip and palate will provide new opportunities to map susceptibility loci for clefts. Genet Med 2008:10(9):668-674.
\end{abstract}

Key Words: cleft lip and palate, tooth agenesis, dental anomalies, oral clefts, ANKS6, SAMD6, ERBB2, IRF6

Isolated or nonsyndromic cleft lip and palate $(\mathrm{CL} / \mathrm{P})$ is a complex disorder resulting from multiple genetic and environmental factors. $\mathrm{CL} / \mathrm{P}$ is a common birth defect and the source of substantial morbidity and mortality worldwide. ${ }^{1}$ With an average birth prevalence of 1/700 live births, there is remarkable population to population variation. ${ }^{2}$ In general, Asian populations have a higher birth prevalence of clefting (1/500 births), whites are intermediate (1/1100), and African populations have the lowest (1/2500 births). However, the notion that Asians have a higher prevalence of clefts has been challenged

\footnotetext{
From the Departments of ${ }^{1}$ Oral Biology and ${ }^{2}$ Pediatric Dentistry, and ${ }^{3}$ Center for Craniofacial and Dental Genetics, School of Dental Medicine, University of Pittsburgh, Pittsburgh; ${ }^{4}$ Department of Human Genetics, Graduate School of Public Health, University of Pittsburgh, Pittsburgh; ${ }^{5}$ Department of Pediatrics, University of Iowa, Iowa City; and ${ }^{6}$ Department of Psychiatry, School of Medicine, University of Pittsburgh, Pittsburgh.

Alexandre R. Vieira, DDS, MS, PhD, Department of Oral Biology, 614 Salk Hall, School of Dental Medicine, University of Pittsburgh, 3501 Terrace Street, Pittsburgh, PA 15261. E-mail:arv11@dental.pitt.edu.

Disclosure: The authors declare no conflict of interest.

Supplementary appendixes are available via the ArticlePlus feature at www.geneticsinmedicine.org. Submitted for publication January 25, 2008.

Accepted for publication June 3, 2008

DOI: $10.1097 /$ GIM.0b013e3181833793
}

based on the evidence that many published prevalence rates included all pregnancies (live and still births) and do not distinguish between syndromic and nonsyndromic clefts, or between cleft palate alone and cleft lip with or without cleft palate. $^{3}$

An examination of familial recurrence patterns in $\mathrm{CL} / \mathrm{P}$ indicated that there may be anywhere from 3 to 14 interacting loci involved in clefting. ${ }^{4}$ This analysis indicates that large sample sizes may be necessary to detect the loci involved in CL/P. For a complex genetic disorder such as $\mathrm{CL} / \mathrm{P}$, several experimental techniques may be used. These include breakpoint mapping, deletion mapping, direct sequencing of candidate genes/loci, linkage analysis, and linkage disequilibrium analysis. ${ }^{5}$ A number of studies on populations with clefts from the Philippines have been productive, in part because of the common occurrence of isolated clefting, large average family sizes, and a motivated public health enterprise. ${ }^{6}$ Studies with the Filipino population included MSX1, ${ }^{7-9}$ transforming growth factor alpha (TGFA), ${ }^{7-9}$ transforming growth factor beta 2 (TGFB2), 7 TGFB3,7,9 interferon regulatory factor 6 (IRF6), ${ }^{10}$ FGF family of genes, ${ }^{11}$ PVRL $1,{ }^{12}$ genes at $19 \mathrm{q} 13,{ }^{13}$ genes at $8 \mathrm{p} 11-23,{ }^{14}$ genes at $9 \mathrm{q} 21,15,16$ and an additional 18 -candidate genes. ${ }^{9}$ Furthermore, a meta-analysis of seven genome scans ${ }^{15}$ 
that included Filipino family data revealed significant linkage signals at 9q21 (heterogeneity logarithm of odds [LOD] score 6.6) and 6q23-25 (heterogeneity LOD score 3.55) among other regions. Even though these studies included as many as 403 families (ranging from 3 to 76 individuals in each), the results were, for the most part, modest. The only exceptions are IRF $6^{10}$ and $M S X 1^{7-9}$. IRF6 has also been consistently associated with $\mathrm{CL} / \mathrm{P}$ in a number of populations. ${ }^{17-22}$ In the same way, MSX1 has been associated with $\mathrm{CL} / \mathrm{P}$ in several independent studies. ${ }^{23-37}$ We hypothesize that increasing the sophistication of the clinical description would allow reducing misclassification and improving ones ability to see associations that may have been otherwise masked by a larger more heterogeneous classification approach. We propose to use the presence of dental anomalies outside of the cleft area to subphenotype clefts. Preliminary analysis suggests that dental anomalies are preferentially associated with clefts in some families, ${ }^{38}$ and gene expression studies show that a number of genes colocalize to the developing tooth and palate. ${ }^{39-42}$ To extend these earlier studies, we proposed to revisit the subset of the initially genotyped families with two or more siblings affected by $\mathrm{CL} / \mathrm{P}$ and perform a dental examination to broaden the phenotypic description of the families.

\section{PATIENTS AND METHODS}

\section{Dental assessments}

Information on dental anomalies outside the cleft area was collected from the cases and all available relatives. Aside from tooth agenesis, which is the most common congenital anomaly in humans and the one we expected to see the most, other dental anomalies included supernumerary teeth, microdontia, macrodontia, missing cusps, and supernumerary cusps. In many instances, tooth agenesis needed confirmation by an $\mathrm{x}$-ray examination for which we used a portable $\mathrm{x}$-ray system (MinXray P200D MarkIII; Toshiba, Tokyo, Japan). In addition, missing teeth due to tooth decay (caries) needed to be distinguished from congenitally missing teeth. We conducted careful examinations and collected comprehensive caries data (data not shown) to aid in the differential diagnosis.

The University of Iowa Institutional Review Board (IRB) (approval \# 200507743) and University of Pittsburgh IRB (approval \# 0511198) gave approval for the study in conjunction with local approval in the Philippines.

Despite local political issues, geographic locations, and weather conditions ( 13 typhoons and severe tropical storms hit the Philippines between May 23rd and December 19th, 2006), we were able to recontact 46 families with two or more siblings affected with cleft lip with or without cleft palate $(\mathrm{CL} / \mathrm{P})$ of the 70 families who we attempted to contact. Forty-two of the 46 families had available genotyping data. All 42 families had additional affected relatives beyond the two or more affected siblings. We collected data on approximately 500 individuals, including 100 unrelated control families that were used to calculate dental anomalies frequency in the general population for our power studies.

\section{Candidate gene association analysis}

Forty-two families for which clinical dental information was available were genotyped for 1489 single nucleotide polymorphisms (SNP). These SNPs included 727 SNPs in 150 candidate genes, 431 spanning 6q23-25, and 331 9q21. The complete list of the markers is presented in the appendix. Genotypes were performed by the Center for Inherited Disease Research using the Illumina bead system. The design of using families with multiple affected individuals (and with additional sib cases of dental anomalies only added in by our study) allowed us to increase the statistical power of the linkage disequilibrium approaches. The candidate genes we have been studying (MSX1, IRF6, PAX9, and FGFR1) are represented in this collection of 500 markers, and other interesting regions. Among the 150 candidate genes are bone morphogenetic protein 2 (BMP2), BMP4, ectodermal growth factor $(E G F)$, and its receptor, $D L X$ family members, FGF1, FGF8, FGF10, MSX2, PVR, PVRL family members, TGFA, TGFB family members and their receptors, SKI, SHH, PTCH, WNT family members, TBX family members, PITX2, and retinoic acid receptor alpha $(R A R A)$.

The data for all SNPs were consistent with Hardy-Weinberg equilibrium in both the affected and unaffected individuals, and in a group of unrelated individuals. Alleles at each marker were tested for association twice under an additive model: (1) first, only those individuals with $\mathrm{CL} / \mathrm{P}$ were considered affected, (2) second, the affection status was broadened to include individuals with dental anomalies who were also assigned as affected. The Family-Based Association Test implemented in the FBAT software package ${ }^{43,44}$ was used in these analyses.

\section{RESULTS}

In the 42 families, there were 519 individuals total. One hundred twenty-eight people were born with CL/P and genotyping data were available for 125 of them. The remaining 391 family members were not affected by $\mathrm{CL} / \mathrm{P}$ and genotyping data were available for 215 of them. Among the 391 unaffected relatives, 48 individuals had dental anomalies (and genotyping data were available for 43 of them).

Tooth agenesis was the most prevalent dental anomaly found in this study. Third molars were the most frequently affected tooth, followed by second premolars. Although other dental anomalies such as supernumerary teeth, microdontia, and supernumerary cusps were found in the families, the affected individuals usually had tooth agenesis as well, or these families always had other family members with tooth agenesis. Only nine probands did not have any relatives with dental anomalies (the other 33 probands had relatives with dental anomalies). However, four probands of the nine did have dental anomalies outside the cleft area themselves. A total of 23 probands had concomitant dental anomalies outside the cleft area.

Table 1 presents all markers with $P$ values 0.05 or below (before multiple test correction) in each of the analyses. An SNP in ankyrin repeat and sterile alpha motif domain containing 6 (ANKS6) (rs4742741, 9q22.33; $P=0.0004)$ was signifi- 
Vieira et al.

Table 1

Most significant linkage disequilibrium results in the cleft lip and palate families with and without dental anomalies as an additional affection status

\begin{tabular}{lllll}
\hline Chromosome & SNP & cM & $P$ & Gene
\end{tabular}

Cleft lip and palate + dental anomalies

\begin{tabular}{|c|c|c|c|c|c|}
\hline \multirow[t]{5}{*}{1} & rs2013162 & 206.3571 & 0.002 & IRF6 & \\
\hline & rs2279455 & 91.89721 & 0.008 & TGFBR3 & \\
\hline & rs674433 & 206.3533 & 0.01 & IRF6 & \\
\hline & rs3738480 & 147.8039 & 0.02 & PRUNE & \\
\hline & rs786908 & 88.96538 & 0.04 & PKN2 & \\
\hline \multirow[t]{2}{*}{2} & rs377122 & 70.67868 & 0.03 & $T G F A$ & \\
\hline & rs7583130 & 202.7306 & 0.04 & SUMO1 & Close to \\
\hline \multirow[t]{2}{*}{3} & rs9849690 & 185.8107 & 0.02 & ЕРHB3 & Close to \\
\hline & rs1515490 & 191.0796 & 0.04 & p63/TP73L & \\
\hline \multirow[t]{2}{*}{4} & rs6841268 & 139.5262 & 0.04 & SLC7A11 & \\
\hline & rs7677751 & 54.96539 & 0.04 & PDGFRA & \\
\hline \multirow[t]{2}{*}{5} & rs4559013 & 170.7842 & 0.04 & FGF18 & \\
\hline & rs3934591 & 170.8002 & 0.05 & FGF18 & \\
\hline \multirow[t]{23}{*}{6} & rs9320231 & 108.1769 & 0.005 & SCML4 & \\
\hline & rs6921044 & 140.3791 & 0.006 & ВC039503 & \\
\hline & rs969282 & 134.2468 & 0.008 & TCF21 & \\
\hline & rs971402 & 112.5946 & 0.008 & LAMA4 & \\
\hline & rs2503791 & 153.7521 & 0.009 & MTRF1L & \\
\hline & rs7772821 & 132.9342 & 0.01 & TAAR6 & \\
\hline & rs9206 & 151.7713 & 0.01 & MTHFD1L & \\
\hline & rs3757316 & 151.8665 & 0.01 & Corf 211 & \\
\hline & rs1555091 & 127.4783 & 0.02 & AK127472 & \\
\hline & rs9491385 & 125.6747 & 0.02 & $I B R D C 1$ & Close to \\
\hline & rs1546943 & 116.6082 & 0.02 & NT5DC1 & \\
\hline & rs485640 & 125.4073 & 0.03 & $I B R D C 1$ & \\
\hline & rs 2503322 & 127.499 & 0.03 & RSPO3 & \\
\hline & rs2811674 & 134.3728 & 0.03 & SLC2A12 & \\
\hline & rs3800223 & 108.6792 & 0.03 & SNX3 & \\
\hline & rs238590 & 115.4712 & 0.03 & HS3ST5 & \\
\hline & rs6570847 & 148.7266 & 0.04 & SASH1 & \\
\hline & rs1741820 & 122.7632 & 0.04 & HSF2 & \\
\hline & rs1267948 & 122.8153 & 0.04 & SERINC1 & \\
\hline & rs576247 & 122.7886 & 0.05 & HSF2 & \\
\hline & rs2802288 & 109.0029 & 0.05 & FOXO3A & \\
\hline & rs6913898 & 151.474 & 0.05 & MTHFD1L & \\
\hline & rs911477 & 109.3696 & 0.05 & $A R M C 2$ & \\
\hline \multirow[t]{4}{*}{9} & Rs4742741 & 98.61916 & 0.0004 & ANKS6 & \\
\hline & rs843258 & 102.6709 & 0.007 & CYLC2 & \\
\hline & rs1930135 & 98.49069 & 0.009 & $G A B B R 2$ & \\
\hline & rs1020884 & 97.23761 & 0.01 & FOXE1 & \\
\hline
\end{tabular}

\begin{tabular}{|c|c|c|c|c|c|}
\hline Chromosome & SNP & $\mathrm{cM}$ & $P$ & Gene & \\
\hline & rs4743088 & 97.23837 & 0.01 & FOXE1 & \\
\hline & rs2636879 & 114.1241 & 0.01 & COL27A1 & \\
\hline & rs4443717 & 107.0198 & 0.01 & ZNF462 & \\
\hline & rs418919 & 99.11206 & 0.02 & TGFBR1 & Close t \\
\hline & rs4129220 & 94.46965 & 0.03 & $F B P 1$ & \\
\hline & rs337572 & 98.5662 & 0.03 & ANKS6 & \\
\hline & rs1555573 & 99.20898 & 0.03 & DQ673940 & \\
\hline & rs773515 & 91.06249 & 0.03 & $A U H$ & \\
\hline & rs3747496 & 97.1669 & 0.03 & KIAA1529 & \\
\hline & rs4743077 & 97.17104 & 0.03 & KIAA1529 & \\
\hline & rs2416682 & 118.5309 & 0.03 & TLR4 & \\
\hline & rs3794486 & 105.5419 & 0.04 & TMEM38B & \\
\hline & rs1979993 & 105.6141 & 0.04 & TMEM $38 B$ & \\
\hline & rs3793524 & 109.299 & 0.04 & PTPN3 & \\
\hline & rs1059273 & 97.92906 & 0.04 & TRIM14 & \\
\hline & rs4743348 & 99.25561 & 0.05 & TGFBR1 & Close to \\
\hline & rs2281732 & 97.92456 & 0.05 & TRIM14 & \\
\hline \multirow[t]{3}{*}{14} & rs 2536143 & 72.25479 & 0.03 & DPF3 & \\
\hline & rs 221430 & 79.13787 & 0.04 & NRXN3 & \\
\hline & rs1018466 & 36.193 & 0.04 & PAX9 & Close to \\
\hline \multirow[t]{4}{*}{15} & rs2879515 & 32.65859 & 0.01 & SLC12A5 & Close to \\
\hline & rs878960 & 24.48003 & 0.02 & GABRB3 & \\
\hline & rs690 & 56.62203 & 0.03 & LIPC & \\
\hline & rs1426223 & 24.50339 & 0.05 & $G A B R B 3$ & \\
\hline \multirow[t]{9}{*}{17} & rs1810132 & 35.11953 & 0.0005 & ERBB2 & \\
\hline & rs2015729 & 42.70949 & 0.002 & ITGB3 & \\
\hline & rs2292699 & 42.71729 & 0.005 & ITGB3 & \\
\hline & rs890397 & 45.45893 & 0.01 & $D L X 3 / D L X 4$ & \\
\hline & rs1905339 & 37.83582 & 0.01 & STAT3 & Close to \\
\hline & rs8071740 & 22.54986 & 0.02 & WSB1 & Close to \\
\hline & rs744166 & 37.76773 & 0.02 & STAT3 & \\
\hline & rs 2313430 & 35.18334 & 0.04 & IKZF3 & \\
\hline & rs9906933 & 37.66357 & 0.04 & STAT5B & \\
\hline 18 & rs2215502 & 24.03802 & 0.02 & $\mathrm{CDH} 2$ & Close t \\
\hline \multirow[t]{2}{*}{20} & rs819133 & 32.33398 & 0.02 & $A H C Y$ & \\
\hline & rs6123674 & 55.19635 & 0.04 & $B M P 7$ & \\
\hline 21 & rs4817579 & 33.83209 & 0.02 & GART & \\
\hline \multicolumn{6}{|c|}{ Cleft lip and palate } \\
\hline \multirow[t]{4}{*}{1} & rs674433 & 206.3533 & 0.001 & IRF6 & \\
\hline & rs2013162 & 206.3571 & 0.001 & IRF6 & \\
\hline & rs513287 & 167.3959 & 0.003 & PRRX1 & \\
\hline & rs 2279455 & 91.89721 & 0.01 & TGFBR3 & \\
\hline
\end{tabular}

(Continued) 
Table 1

Continued

\begin{tabular}{|c|c|c|c|c|c|}
\hline Chromosome & SNP & $\mathrm{cM}$ & $P$ & Gene & \\
\hline & rs 4245660 & 78.25275 & 0.02 & GIPC2 & \\
\hline & rs1051740 & 222.3264 & 0.03 & EPHX1 & \\
\hline & rs786908 & 88.96538 & 0.03 & PKN2 & \\
\hline & rs 1007512 & 75.2837 & 0.05 & LHX8 & Close to \\
\hline \multirow[t]{7}{*}{2} & rs7583130 & 202.7306 & 0.01 & SUMO1 & Close to \\
\hline & rs4328603 & 9.611782 & 0.01 & ADAM17 & \\
\hline & rs2280509 & 202.7229 & 0.03 & FZD7 & \\
\hline & rs6705408 & 9.580829 & 0.03 & ADAM17 & \\
\hline & rs2276338 & 9.596387 & 0.03 & $A D A M 17$ & \\
\hline & rs377122 & 70.67868 & 0.04 & TGFA & \\
\hline & rs512535 & 21.17943 & 0.04 & OSR1 & Close to \\
\hline 3 & rs9849690 & 185.8107 & 0.02 & EPHB3 & Close to \\
\hline 5 & rs7715062 & 7.959907 & 0.04 & $M T R R$ & Close to \\
\hline \multirow[t]{19}{*}{6} & rs2503791 & 153.7521 & 0.003 & MTRF1L & Close to \\
\hline & rs971402 & 112.5946 & 0.003 & LAMA4 & \\
\hline & rs7772821 & 132.9342 & 0.005 & TAAR6 & \\
\hline & rs9320231 & 108.1769 & 0.01 & SCML4 & \\
\hline & rs6921044 & 140.3791 & 0.01 & ВС039503 & \\
\hline & rs969282 & 134.2468 & 0.02 & TCF21 & Close to \\
\hline & rs1546943 & 116.6082 & 0.02 & NT5DC1 & \\
\hline & rs1983721 & 117.0122 & 0.02 & RWDD1 & \\
\hline & rs485640 & 125.4073 & 0.02 & $I B R D C 1$ & \\
\hline & rs911477 & 109.3696 & 0.03 & $A R M C 2$ & \\
\hline & rs718174 & 108.4799 & 0.03 & OSTM1 & \\
\hline & rs3734679 & 107.6221 & 0.03 & PDSS2 & \\
\hline & rs2503322 & 127.499 & 0.03 & RSPO3 & \\
\hline & rs3800229 & 109.1037 & 0.03 & FOXO3A & \\
\hline & rs2811674 & 134.3728 & 0.03 & SLC2A12 & \\
\hline & rs3127657 & 107.2111 & 0.04 & QRSL1 & \\
\hline & rs549332 & 116.5613 & 0.04 & NT5DC1 & \\
\hline & rs1555091 & 127.4783 & 0.04 & AK127472 & \\
\hline & rs9400504 & 112.213 & 0.04 & $F Y N$ & \\
\hline \multirow[t]{2}{*}{8} & rs6987534 & 38.41887 & 0.02 & FGFR1 & \\
\hline & rs3925 & 38.40082 & 0.03 & FGFR1 & \\
\hline \multirow[t]{8}{*}{9} & rs 4742741 & 98.61916 & 0.001 & ANKS6 & \\
\hline & rs418919 & 99.11206 & 0.005 & TGFBR1 & Close to \\
\hline & rs1020884 & 97.23761 & 0.01 & FOXE1 & Close to \\
\hline & rs 4743088 & 97.23837 & 0.01 & FOXE1 & Close to \\
\hline & rs2636879 & 114.1241 & 0.01 & COL27A1 & \\
\hline & rs1930135 & 98.49069 & 0.01 & GABBR2 & \\
\hline & rs4129220 & 94.46965 & 0.01 & $F B P 1$ & \\
\hline & rs2281732 & 97.92456 & 0.02 & TRIM14 & \\
\hline
\end{tabular}

\begin{tabular}{|c|c|c|c|c|c|}
\hline Chromosome & SNP & $\mathrm{cM}$ & $P$ & Gene & \\
\hline & rs1059273 & 97.92906 & 0.02 & TRIM14 & \\
\hline & rs 843258 & 102.6709 & 0.02 & CYLC2 & \\
\hline & rs1555573 & 99.20898 & 0.02 & DQ673940 & \\
\hline & rs995294 & 109.8189 & 0.03 & PALM2-AKAP2 & \\
\hline & rs3794486 & 105.5419 & 0.03 & TMEM38B & \\
\hline & rs3750396 & 88.85173 & 0.03 & $A K 127258$ & \\
\hline & rs4743348 & 99.25561 & 0.03 & TGFBR1 & Close to \\
\hline & rs1320547 & 93.79928 & 0.04 & $B A R X 1$ & Close to \\
\hline & rs 1462090 & 97.24908 & 0.05 & FOXE1 & Close to \\
\hline & rs773515 & 91.06249 & 0.05 & $A U H$ & \\
\hline 11 & rs 10790332 & 119.0589 & 0.02 & PVRL1 & \\
\hline \multirow[t]{2}{*}{12} & rs11065374 & 119.8629 & 0.01 & TCF1 & Close to \\
\hline & rs1039302 & 119.699 & 0.02 & UNQ1887 & \\
\hline 14 & rs1018466 & 36.193 & 0.01 & PAX9 & Close to \\
\hline 15 & rs690 & 56.62203 & 0.02 & LIPC & \\
\hline \multirow[t]{7}{*}{17} & rs1810132 & 35.11953 & 0.0006 & $E R B B 2$ & \\
\hline & rs2015729 & 42.70949 & 0.001 & ITGB3 & \\
\hline & rs2292699 & 42.71729 & 0.01 & ITGB3 & \\
\hline & rs890397 & 45.45893 & 0.01 & $D L X 3 / D L X 4$ & Close to \\
\hline & rs2056131 & 42.68874 & 0.01 & ITGB3 & \\
\hline & rs8071740 & 22.54986 & 0.01 & WSB1 & Close to \\
\hline & rs4461115 & 43.15458 & 0.03 & ITGB3 & Close to \\
\hline 18 & rs2215502 & 24.03802 & 0.003 & $\mathrm{CDH} 2$ & Close to \\
\hline
\end{tabular}

cantly over-transmitted when the dental anomalies were added to the analysis. Another significantly over-transmitted SNP was seen in ERBB2 (rs1810132, 17q21.1; $P=0.0006$ ). In the clefts only analysis, an SNP in ERBB2 was significantly overtransmitted $(P=0.0006)$. Other markers with interesting $P$ values included $I R F 6, C D H 2$, and 6q21-q23 loci (Table 1). Table 2 highlights the differences found between the two analyses performed. In summary, many of the over-transmitted SNPs were seen under both analysis (cleft only versus cleft plus dental anomalies), but notably the loci 14q24.3-q31.1 (DPF3 and neurexin 3[NRXN3]) and 21q22.11 (GART) showed evidence for over-transmission only with the addition of dental anomaly phenotypes in the analysis.

\section{DISCUSSION}

Our results from the candidate gene data suggest that dental anomalies are part of an extended cleft phenotype. In addition, some genes may contribute to clefts in association with dental anomalies. However, there are obvious limitations in our study. Although the Filipino families included in our study tend to have large sibships, it was not always possible to examine all potential subjects in all families. A number of reasons 
Table 2

Contrasting results between the two candidate genes/association analyses

\begin{tabular}{|c|c|c|c|c|}
\hline Locus & Gene & SNP & CLP Data $(P)$ & CLP + dental anomalies data $(P)$ \\
\hline \multicolumn{5}{|c|}{ Loci where association is present in both clefts and clefts + dental anomalies data } \\
\hline \multirow[t]{6}{*}{$9 q 22.33$} & ANKS6 & rs4742741 & 0.001 & 0.0004 \\
\hline & $C Y L C 2$ & rs843258 & 0.02 & 0.008 \\
\hline & GABRB2 & rs1930135 & 0.01 & 0.009 \\
\hline & TGFBR1 & rs418919 & 0.005 & 0.02 \\
\hline & FOXE1 & rs1020884 & 0.01 & 0.01 \\
\hline & FOXE1 & rs4743088 & 0.01 & 0.01 \\
\hline \multirow[t]{3}{*}{$17 \mathrm{q} 21.1$} & $E R B B 2$ & rs1810132 & 0.0006 & 0.0006 \\
\hline & ITGB3 & rs2015729 & 0.002 & 0.003 \\
\hline & ITGB3 & rs2292699 & 0.01 & 0.005 \\
\hline \multirow[t]{2}{*}{$1 \mathrm{q} 32.3-\mathrm{q} 41$} & IRF6 & rs2013162 & 0.002 & 0.002 \\
\hline & IRF6 & rs674433 & 0.001 & 0.01 \\
\hline \multirow[t]{6}{*}{$6 \mathrm{q} 21-\mathrm{q} 23$} & SCML4 & rs9320231 & 0.01 & 0.006 \\
\hline & ВС039503 & rs6921044 & 0.01 & 0.006 \\
\hline & TCF21 & rs969282 & 0.02 & 0.008 \\
\hline & LAMA4 & rs971402 & 0.003 & 0.008 \\
\hline & MTRFL1 & rs 2503791 & 0.003 & 0.009 \\
\hline & TAAR6 & rs7772821 & 0.005 & 0.01 \\
\hline $2 \mathrm{p} 13$ & $T G F A$ & rs377122 & 0.04 & 0.03 \\
\hline \multicolumn{5}{|c|}{ Loci where association is stronger in the clefts + dental anomalies than that in the clefts data } \\
\hline \multirow[t]{2}{*}{$5 q 34$} & FGF18 & rs 4559013 & 0.09 & 0.05 \\
\hline & FGF18 & rs3934591 & 0.1 & 0.05 \\
\hline \multirow[t]{2}{*}{$14 \mathrm{q} 24.3-\mathrm{q} 31.1$} & DPF3 & rs 2536143 & 0.18 & 0.03 \\
\hline & NRXN3 & rs221430 & 0.32 & 0.04 \\
\hline \multirow[t]{4}{*}{$15 \mathrm{q} 11.2-\mathrm{q} 12$} & SLC12A5 & rs2879515 & 0.06 & 0.01 \\
\hline & GABRB3 & rs 878960 & 0.06 & 0.02 \\
\hline & GABRB3 & rs1426223 & 0.06 & 0.05 \\
\hline & LIPC & rs690 & 0.02 & 0.04 \\
\hline \multirow[t]{2}{*}{$20 \mathrm{q} 13$} & $A H C Y$ & rs819133 & 0.06 & 0.02 \\
\hline & $B M P 7$ & rs6123674 & 0.07 & 0.04 \\
\hline $21 \mathrm{q} 22.11$ & GART & rs4817579 & 0.16 & 0.02 \\
\hline
\end{tabular}

account for that, such as having a job in another city and not being available at the time of data collection, or choosing not to participate in the study. Another limitation is that this family dataset is probably not representative of the Filipino population. Although it is possible that this group of families may be representative of the Cebu province or even the Central Visayas region, the lack of official population-based records of birth defects in the Philippines does not allow us to make any assumptions regarding the Filipino population as a whole.

The association we found between families with clefts and IRF6 confirms our previous work ${ }^{10}$ with this same population. It is remarkable that the association is still evident with only 42 families, which corroborates that IRF6 is a major contributor to clefts in Filipinos. Although concerned about multiple testing, we did not apply the strict Bonferroni correction as it would increase type II errors and a major focus of this study was to identify putative associations with the combined dental anomaly/cleft phenotype for further studies. For example, under the Bonferroni correction, we would have lowered the alpha to $0.00003(0.05 / 1489)$ and the known association with IRF6 $(P=0.001)$ would have been missed. Therefore, here we report all results with $P$ values below 0.05 . However, our data must be carefully interpreted because it is expected that some of the $P$ values below 0.05 can be due to chance. 
Analyses under both the narrow and broad affection statuses resulted in significant evidence of over-transmission for markers in 6q21-q23.2, 9q21, and 17q12. The 6q21-q23.2 and 9q21 regions previously showed linkage to clefts in a meta-analysis of genome-wide scan data from seven populations. ${ }^{15}$ In the current study, markers in 6q21-q23.2 yielded $P$ values between 0.009 and 0.003 , and those in $9 \mathrm{q} 21$ yielded $P$ values between 0.009 and 0.0004 . The most significantly over-transmitted marker in 9q21 was rs4742741 in ANKS6 located at 9q22.33 ( $P=0.001$ for clefts only, and $P=0.0004$ for clefts and dental anomalies). Adrenomedulin, a vasodilator peptide, prevents the suppression of the inhibitory SMAD6 (mothers against decapentaplegic [SMAD], mother against decapentaplegic, homolog 6) protein by TGFB1 and restores SMAD2-ANKS6 complex formation in human renal tubular epithelial cell lines. ${ }^{45}$ TGFB/BMP signals rely on SMAD-dependent pathways in the ectomesenchyme to mediate epithelial-mesenchymal interactions that control the first branchial arch patterning and tooth development. ${ }^{46}$

The rs 1810132 marker in ERBB2 (receptor tyrosine-protein kinase erbB-2, precursor), located in $17 \mathrm{q} 12$, yielded $P$ values of 0.0006 . Previous work has suggested that RARA, located at $17 \mathrm{q} 21.1$, is associated with isolated CL/P. ${ }^{47,48}$ ERBB2 is 642,088 base pairs upstream from RARA. Because they are relatively near to each other, the previous association suggested for $R A R A$ could actually be due to variation in ERBB2. ERBB2 is an essential component of a neuregulin-receptor complex but it is not activated by EGF or TGFA. Erbb2-deficient mice die at birth and display defects in presynaptic development. ${ }^{49}$ Ethanol consumption during pregnancy affects the expression of Erbb2 and induces a delay in murine fetal dental morphogenesis. ${ }^{50} E R B B 2$ has not been previously considered as a candidate gene for clefts.

In contrast to the above results, suggestive over-transmission of markers in GART (phosphoribosylglycinamide formyltransferase, phosphoribosylglycinamide synthetase, and phosphoribosylaminoimidazole synthetase), DPF3 (D4, zinc and double plant homeo domain fingers, family 3 ), and NRXN3 were seen only when the dental anomaly phenotype was included in the analysis. These genes have not been shown to be expressed during tooth development and their function is still largely unknown. According to the Entrez database, GART is required for de novo purine biosynthesis, $N R X N 3$ functions in the vertebrate nervous system as cell adhesion molecules and receptors, and DPF3 is probably involved in RNA transcription.

In summary, our results support the hypothesis that increasing the complexity of the clinical description by adding dental anomalies information will provide new opportunities to map susceptibility loci for clefts. Here we report, for the first time, an extensive candidate gene analysis for cleft susceptibility loci using dental anomalies to subphenotype clefts. This approach seems to be a promising one and may help in the identification of genetic variants that increase cleft susceptibility, which would be a crucial step that may allow better estimates of recurrence risks for individual families.

\section{ACKNOWLEDGMENTS}

This work was supported by the NIH Grants R21-DE016718, R37-DE08559, R01-DE016148, P50-DE016215, and CIDR NIH contract N01-HG-65403 (genotyping).

The authors are indebted to the families that participated in this study. The Phenomics Group of the Philippines, Inc. facilitated the field work. Andrew Lidral helped in providing access to the genotype data.

\section{References}

1. Murray JC. Gene/environment causes of cleft lip and/or palate. Clin Genet 2002;61: $248-256$.

2. Mossey PA, Little J. Epidemiology of oral clefts: an international perspective. In: Wyszynski DF, editor. Cleft lip and palate. From origin to treatment. New York: Oxford University Press, 2002:127-158.

3. Cooper ME, Ratay JS, Marazita ML. Asian oral-facial cleft birth prevalence. Cleft Palate Craniofac J 2006;43:580-589.

4. Schliekelman P, Slatkin M. Multiplex relative risk and estimation of the number of loci underlying an inherited disease. Am J Hum Genet 2002;71:1369-1385.

5. Lidral AC, Murray JC. Genetic approaches to identify disease genes for birth defects with cleft lip/palate as a model. Birth Defects Res A Clin Mol Teratol 2004;70:893-901.

6. Murray JC, Daack-Hirsch S, Buetow KH, et al. Clinical and epidemiologic studies of cleft lip and palate in the Philippines. Cleft Palate Craniofac J 1997;34:7-10.

7. Lidral AC, Murray JC, Buetow KH, et al. Studies of the candidates genes TGFB2, MSX1, TGFA, and TGFB3 in the etiology of cleft lip and palate in the Philippines. Cleft Palate Craniofac J 1997;34:1-6.

8. Jezewski PA, Vieira AR, Nishimura C, et al. Complete sequencing shows a role for MSX1 in non-syndromic cleft lip and palate. J Med Genet 2003;40:399-407.

9. Vieira AR, Avila JR, Daack-Hirsch S, et al. Medical sequencing of candidate genes for nonsyndromic cleft lip and palate. PLoS Genet 2005a;1:e64.

10. Zucchero TM, Cooper ME, Maher BS, et al. Interferon regulatory factor 6 (IRF6) gene variants and the risk of isolated cleft lip and palate. N Engl J Med 2004;351:769780.

11. Riley BM, Mansilla MA, Ma J, et al. Impaired FGF signaling contributes to cleft lip and palate. Proc Natl Acad Sci USA 2007;104:4512-4517.

12. Avila JR, Jezewski PA, Vieira AR, et al. PVRL1 variants contribute to nonsyndromic cleft lip and palate in multiple populations. Am J Med Genet 2006;140:2562-2570.

13. Warrington A, Vieira AR, Christensen K, et al. Genetic evidence for the role of loci at $19 q 13$ in cleft lip and palate. J Med Genet 2006;43:e26.

14. Riley BM, Schultz RE, Cooper ME, et al. A genome-wide linkage scan for cleft lip and cleft palate identifies a novel locus on 8p11-23. Am J Med Genet 2007;143A:846852.

15. Marazita ML, Murray JC, Lidral AC, et al. Meta-analysis of 13 genome scans reveals multiple cleft lip/palate genes with novel loci on 9q21 and 2q32-35. Am J Hum Genet 2004;75:161-173.

16. Mansilla MA, Cooper ME, Goldstein T, et al. Contributions of PTCH gene variants to isolated cleft lip and palate. Cleft Palate Craniofac J 2006;43:21-29.

17. Blanton SH, Cortez A, Stal S, Mulliken JB, Finnell RH, Hecht JT. Variation in IRF6 contributes to nonsyndromic cleft lip and palate. Am J Med Genet 2005;137A:259262.

18. Ghassibé M, Bayet B, Revencu N, et al. Interferon regulatory factor-6: a gene predisposing to isolated cleft lip with or without cleft palate in the Belgian population. Eur J Hum Genet 2005;13:1239-1242.

19. Scapoli L, Palmieri A, Martinelli M, et al. Strong evidence of linkage disequilibrium between polymorphisms at the IRF6 locus and nonsyndromic cleft lip with or without cleft palate, in an Italian population. Am J Hum Genet 2005;76:180-183.

20. Srichomthong C, Siriwan P, Shotelersuk V. Significant association between IRF6 $820 \mathrm{G}->\mathrm{A}$ and non-syndromic cleft lip with or without cleft palate in the Thai population. J Med Genet 2005;42:e46.

21. Park JW, McIntosh I, Hetmanski JB, et al. Association between IRF6 and nonsyndromic cleft lip with or without cleft palate in four populations. Genet Med 2007;9: 219-227.

22. Vieira AR, Cooper ME, Marazita ML, Orioli IM, Castilla EE. Interferon regulatory factor 6 (IRF6) is associated with oral-facial cleft in individuals that originate in South America. Am J Med Genet 2007;143A:2075-2078.

23. Lidral AC, Romitti PA, Basart AM, et al. Association of MSX1 and TGFB3 with nonyndromic clefting in humans. Am J Hum Genet 1998;63:557-568.

24. Romitti PA, Lidral AC, Munger RG, Daack-Hirsch S, Burns TL, Murray JC. Candidate genes for nonsyndromic cleft lip and palate and maternal cigarette smoking and alcohol consumption: evaluation of genotype-environment interactions from a population-based case-control study of orofacial clefts. Teratology 1999;59:39-50. 
25. Beaty TH, Wang H, Hetmanski Jb, et al. A case-control study of nonsyndromic oral clefts in Maryland. Ann Epidemiol 2001;11:434-442.

26. Blanco R, Chakraborty R, Barton SA, et al. Evidence of a sex-dependent association between the MSX1 locus and nonsyndromic cleft lip with or without cleft palate in the Chilean population. Hum Biol 2001;73:81-89.

27. Beaty TH, Hetmanski JB, Zeiger JS, et al. Testing candidate genes for non-syndromic oral clefts using a case-parent trio design. Genet Epidemiol 2002;22:1-11.

28. Fallin MD, Hetmanski JB, Park J, et al. Family-based analysis of MSX1 haplotypes for association with oral clefts. Genet Epidemiol 2003;25:168-175.

29. Jugessur A, Lie RT, Wilcox AJ, et al. Variants of developmental genes (TGFA, TGFB3, and MSX1) and their associations with orofacial clefts: a case-parent triad analysis. Genet Epidemiol 2003;24:230-239.

30. Slayton RL, Williams L, Murray JC, Wheeler JJ, Lidral AC, Nishimura CJ. Genetic association studies of cleft lip and/or palate with hypodontia outside the cleft region. Cleft Palate-Craniofac J 2003;40:274-279.

31. Vieira AR, Orioli IM, Castilla EE, Cooper ME, Marazita ML, Murray JC. MSX1 and TGFB3 contribute to clefting in South America. J Dent Res 2003;82:289-292.

32. Suazo J, Santos JL, Carreño H, Jara L, Blanco R. Linkage disequilibrium between MSX1 and non-syndromic cleft lip/palate in the Chilean population. J Dent Res 2004;83:782-785

33. Suzuki Y, Jezewski PA, Machida J, et al. In a Vietnamese population, MSX1 variants contribute to cleft lip and palate. Genet Med 2004;6:117-125.

34. Modesto A, Moreno LM, Krahn K, King S, Lidral AC. MSX1 and orofacial clefting with and without tooth agenesis. J Dent Res 2006;85:542-546.

35. Tongkobpetch S, Siriwan P, Shotelersuk V. MSX1 mutations contribute to nonsyndromic cleft lip in a Thai population. J Hum Genet 2006;51:671-676.

36. Park J, Park BY, Kim HS, et al. MSX1 polymorphism associated with risk of oral cleft in Korea: evidence form case-parent trio and case-control studies. Yonsei Med J 2007;48:101-108.

37. Wu PA, Li YL, Fan GZ, Wang K. Association study on microsatellite polymorphisms of MSX1 gene and nonsyndromic cleft lip and palate. Zhonghua Yi Xue Yi Chuan Xue Za Zhi 2007;24:325-327.

38. Letra A, Menezes R, Granjeiro JM, Vieira AR. Defining subphenotypes for oral clefts based on dental development. J Dent Res 2007;86:986-991.
39. Peters H, Neubüser A, Kratochwil K, Bailing R. Pax9-deficient mice lack pharyngeal pouch derivatives and teeth and exhibit craniofacial and limb abnormalities. Genes Dev 1998;12:2735-2747.

40. Kondo S, Schutte BC, Richardson RJ, et al. Mutations in interferon regulatory factor 6 cause van der woude and popliteal pterygium syndromes. Nat Genet 2002;32:285-289.

41. Zhang Z, Song Y, Zhao X, Zhang X, Fermin C, Chen Y. Rescue of cleft palate in Msx1deficinet mice by transgenic Bmp4 reveals a network of BMP and Shh signaling in the regulation of mammalian palatogenesis. Development 2002;129:4135-4146.

42. Rice R, Thesleff I, Rice DP. Regulation of twist, snail, and Id 1 is conserved between the developing murine palate and tooth. Dev Dyn 2005;234:28 -35.

43. Horvath S, Xu X, Laird NM. The family based association test method: strategies for studying general genotype-phenotype associations. Eur J Hum Genet 2001;9:301-306.

44. Horvath S, Xu X, Lake SL, Silverman EK, Weiss ST, Laird NM. Family-based tests for associating haplotypes with general phenotype data: application to asthma genetics. Genet Epidemiol 2004;26:61-69.

45. Huang H, Ma C, Yang M, Tang C, Wang H. Adrenomedullin impairs the profibrotic effects of transforming growth factor-beta 1 through recruiting Smad6 protein in human renal tubular cells. Cell Physiol Biochem 2005;15:117-124.

46. Ko SO, Chung IH, Xu X, Oka S, Deng C, Chai Y. Smad-dependent TGF-B/BMP signaling in regulating first branchial arch patterning and tooth development. Eur Cells Material 2007;14:23.

47. Chenevix-Trench G, Jones K, Green AC, Duffy DL, Martin NG. Cleft lip with or without cleft palate: associations with transforming growth factor alpha and retinoic acid receptor loci. Am J Hum Genet 1992;51:1377-1385.

48. Peanchitlertkajorn S, Cooper ME, Liu YE, Field LL, Marazita ML. Chromosome 17: gene mapping studies of cleft lip with or without cleft palate in Chinese families. Cleft Palate Craniofac J 2003;40:71-79.

49. Lin W, Sanchez HB, Deerinck T, Morris JK, Ellisman M, Lee KF. Aberrant development of motor axons and neuromuscular synapses in erbB2-deficient mice. Proc Natl Acad Sci USA 2000;97:1299-1304.

50. Jiménez-Farfán D, Guevara J, Zenteno E, Malagón H, Hernández-Guerrero JC. EGF-R and erbB-2 in murine tooth development after ethanol exposure. Birth Defects Res A Clin Mol Teratol 2005;73:65-71. 